\title{
Numerical Investigation of Wave-Frequency Pontoon Responses of a Floating Bridge Based on Model Test Results
}

\author{
Shao, Yanlin; Xiang, Xu ; Liu, Jianyu
}

Published in:

38th International Conference on Ocean, Offshore \& Arctic Engineering

Link to article, DOI:

10.1115/OMAE2019-96545

Publication date:

2019

Document Version

Peer reviewed version

Link back to DTU Orbit

Citation (APA):

Shao, Y., Xiang, X., \& Liu, J. (2019). Numerical Investigation of Wave-Frequency Pontoon Responses of a Floating Bridge Based on Model Test Results. In 38th International Conference on Ocean, Offshore \& Arctic Engineering (Vol. Volume 1: Offshore Technology; Offshore Geotechnics). [OMAE2019-96545] American Society of Mechanical Engineers. https://doi.org/10.1115/OMAE2019-96545

\section{General rights}

Copyright and moral rights for the publications made accessible in the public portal are retained by the authors and/or other copyright owners and it is a condition of accessing publications that users recognise and abide by the legal requirements associated with these rights.

- Users may download and print one copy of any publication from the public portal for the purpose of private study or research.

- You may not further distribute the material or use it for any profit-making activity or commercial gain

- You may freely distribute the URL identifying the publication in the public portal 


\title{
${ }^{* * *}$ accepted final
}

\section{OMAE2019-96545}

\section{NUMERICAL INVESTIGATION OF WAVE-FREQUENCY PONTOON RESPONSES OF A FLOATING BRIDGE BASED ON MODEL TEST RESULTS}

\author{
Yanlin Shao ${ }^{\mathrm{a}}$, Xu Xiang ${ }^{\mathrm{b}}$ and Jianyu Liu ${ }^{\mathrm{c}}$ \\ a Technical University of Denmark, Lyngby, Denmark \\ b Norwegian Public Roads Administration, Oslo, Norway \\ c Harbin Engineering University, Harbin, China
}

\begin{abstract}
The wave-induced responses in the bridge girder of long floating bridges supported by pontoons are often dominated by the vertical modes, coupled horizontal modes and rotational modes about the longitudinal axis of the bridge girder. Pontoons with and without bottom flanges have been seen in recent floating bridge designs. Viscous flow separation around the sharp edges of the pontoon or the bottom flange may have strong influences on the hydrodynamic performance of the pontoon in terms of wave excitation, added mass and damping effects. Morisontype wave and current loads are normally included empirically in the early design phases to account for the viscous effects that cannot be covered by a potential-flow solution alone. Empirical drag coefficients and perhaps a correction to the potential-flow added mass are the inputs to such numerical models, which represents a part of the modelling uncertainties. Previous sensitivity studies using different drag coefficients in the ongoing Bjørnafjord floating bridge project in Norway indicate an influence up to $15 \%$ on the maximum vertical bending moment around the weak axis of the bridge girder.
\end{abstract}

This paper contributes to the understanding of viscous effects on the hydrodynamic characteristics, e.g. the added mass, damping and wave excitation loads, of a floating bridge pontoon with and without keel plate. This is achieved by exploring existing model tests for floating bridge pontoons, performing 2D Computational Fluid Dynamic (CFD) analysis for pontoon cross sections and numerical calibration in a simplified frequency-domain model with linearized drag loads. Scale effects are also investigated through CFD analyses in model and full scales.

\section{INTRODUCTION}

Compared to a ferry, a bridge is a faster and more efficient means of transportation between islands or across fjords. The Øresund Bridge between Denmark and Sweden has proven to benefit both countries by allowing increased commuting at lower expenses. A floating bridge is a good option when it is impossible to use conventional bridges. The floating bridge is typically supported by many pontoons that float above the water, and possibly secured by mooring lines anchored to the seafloor. See Fig. 1(a) for an illustration. Floating bridges without side anchoring system are usually called 'end-anchored floating bridge'. Both of the floating bridges installed in Norway are of this type. Another example of floating bridge is the Evergreen Point Floating Bridge across Lake Washington, which was completed and opened in April 2016 [1]. As a part of the Norwegian Public Road Administration's (NPRA) project to improve the road system between Kristiansand and Trondheim, eight fjords must be crossed, either by tunnels or bridges. As an example, the Bjørnafjord has a width of $4.5 \mathrm{~km}$ with a maximum water depth of $500 \mathrm{~m}$.

For fjords with significant wind and waves, structural design of the bridge girder is governed by the combination of permanent loads and dominant environmental loads with, for instance, a 100-year return period. For the Bjørnafjord floating bridge designs, most of the estimated 
costs of the floating bridge are connected to the cost of steel in the bridge girder. Thus, optimization of induced moments from environmental loads is an important driver. The current paper discusses mainly the phase- 2 design of the Bjørnafjord floating bridge and now the design is in the process of phase- 5 . For the response around this bridge's weak axis, wave loads induce large moments while wind loads are smaller. For the response around the bridge's strong axis, the wind loads are more important than the wave-induced loads.
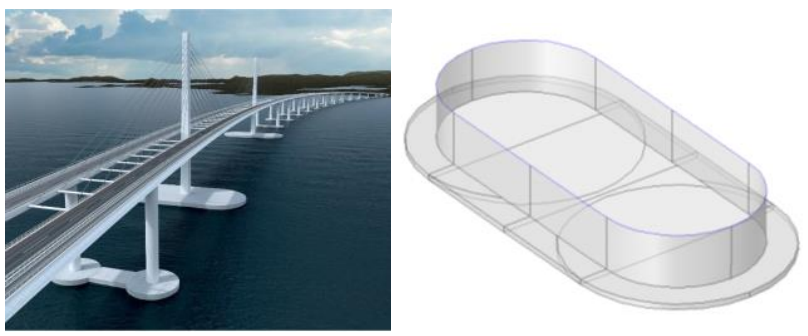

Fig. 1 (a) Artist's impression of the bridge over Bjørnafjord. (b) Example of pontoon with bottom flange.

In order to minimize the weak-axis moments, the pontoonbridge interaction in waves must be assessed. The key to pontoon optimization is to ensure that the eigen-mode induced moments about the bridge's weak axis are not triggered. Inspired by proven designs from the offshore oil \& gas industry, for instance the bilge box used on cylindrical FPSOs [2] and the Spar platform [3], Xiang et al. [4] proposed adding a flange to the bottom of the pontoon. Fig. 1(b) presents an example of a pontoon with a bottom flange. It has been shown in [5] and [6] for Bjørnafjord project that the heave motion eigen-periods can be limited to between $7.8 \mathrm{~s}$ and $10.8 \mathrm{~s}$, where wave loads are minimal. In comparison, the same pontoon without the flange attached has a range of possible heave motion eigenperiods between $6.4 \mathrm{~s}$ and $8.9 \mathrm{~s}$, which is in a range where wave loads are significant. It was also demonstrated in [7] and [8] by using a simplified wave-load model that a bottom flange can increase the added mass of the pontoon significantly, and thus increase the lower natural periods of vertical modes so that they are lifted outside the winddriven wave frequency regime.

The modification of the pontoon by adding a bottom flange is novel for floating bridge designs, and has not yet been applied in existing floating bridges. This modification is therefore considered an unproven technology. However, since the cost of a floating bridge is driven by the expenses of the steel in the bridge girder, if the new pontoon design proves itself effective, it will bring significant cost savings to current floating bridge designs. The cost for the Evergreen Point Floating Bridge was more than 4.75 billion US dollars [1]. A reduction of just a few percent in the total cost would therefore translate into huge financial savings.

In references [7] and [8], the global wave loads were calculated using potential flow theory with empirical corrections to account for viscous effects. The viscous effects were modelled by the so-called Morison's equation. In [5] and [6], the viscous effects were neglected as a conservative approach. This type of model has been commonly used in the design of offshore structures and has been shown to be reasonably accurate for typical designwave conditions (usually 100-year storms). The usefulness of this method is however, not clear for floating bridge pontoons as the design waves in fjords are much shorter and smaller than those in offshore projects. On the other hand, if the simplified method proves to be useful, it is still not clear if the existing empirical drag coefficients reported in the literature for other similar offshore structures can be directly used for the floating pontoons.

To the knowledge of the authors in wave loads, neither project work in the fjords-crossing projects (see e.g. [5] and [6]) nor academic studies on wave loads on floating bridge pontoons (see e.g. [7] and [11]) have addressed the uncertainty related to the simplified wave-load model for assessing the structural performance of floating bridges. However, previous sensitivity studies (see [4] and [12]) using different drag coefficients in the ongoing Bjørnafjord floating bridge project in Norway indicate an influence up to $15 \%$ on the maximum vertical bending moment around the weak axis of the bridge girder.

One concern is that the simplified wave-load model completely ignores the changes in added mass due to viscous effects. Such influences have been observed in model tests of similar structures (see [9] and [10]). Accurate estimation of the increase in added mass due to a bottom flange is key to improve the design by lifting the lower, vertical natural frequencies out of the wave frequency regime. The second concern is if the drag coefficients have been selected properly, as they are different in different flow regimes. The drag coefficients matter for both damping and the viscous excitation wave forces due to the presence of the bottom flange. In particular, the role of the viscous wave excitation forces on the flanges is still unknown. In addition, the scale effects for the floating bridge pontoons are not clear, which matters when one wants to apply the findings from model tests to real projects. Lastly, the uncertainties related to the applied simplified approach and its influence on the global structural performance are unknown, and require further investigation.

To verify and calibrate the analysis tools and methods that are been used in pontoon design, model tests for different individual floating pontoon concepts without bridge girder have been carried out in the ocean basin of SINTEF Ocean as part of the Norwegian Public Road Administration (NPRA) floating bridge project. The experiments were carried out using representative wave conditions in fjords, and the 3D models were built in accordance with similar designs for Bjørnafjord floating bridge project in Norway. 
The model test was specially designed to estimate the added mass, linearized damping and wave excitation loads, respectively. The model test results for pontoon with and without bottom flange will be presented later in Section 5 together with numerical results based on a simplified frequency domain approach with linearized drag loads.

CFD analyses with turbulence modelling will also be performed for a mid-ship cross section of the pontoon design with a bottom flange. The estimated drag coefficients are compared with some existing results for wall-mounted plates from the literature, which shows good agreement considering the differences in the configuration. The scale effects in terms of viscous wave loads are also studied based on the CFD results in model and full scales.

Finally, a simplified procedure in the frequency-domain [2] is followed, which uses the potential-flow hydrodynamic coefficients from, e.g. WADAM, and the equivalently linearized drag loads. For the studied cases, it is found that using the $K C$-dependent drag coefficients, which take into account the total drag on bottom plate, significantly improve the calculated equivalent damping coefficients.

\section{MODEL TEST}

\subsection{Model description}

On behalf of NPRA, SINTEF Ocean has carried out model tests for two different pontoon concepts, i.e. a semi type and an elliptical type with/without bottom plate, in the ocean basin. A 6-DOF forced motions mechanism was applied in the tests for holding or applying the forced motions on the model. The system records the motions and the forces at the same time. A special check was carried out with the eigen periods of the whole system (model + testing rig + roof structure) for ensuring that the system is stiff enough, thus the eigen periods of the system will be safely out of model test periods.

The waves (and current) applied in the model tests were pre-calibrated, representing the incoming (undisturbed) waves. An important note here is that the model scale waves in this test are relative short, and the linearity of these waves are ensured by using a smaller wave height.

Since this paper focuses only on the later concept(s), only information on elliptical pontoon concept will be provided hereafter. More details on the model tests are given in [13].

Table 1 Overview of pontoon types relevant for this study [13].

\begin{tabular}{l|llcc}
\hline Config. & Info. & $\begin{array}{l}\text { Size } \\
(\boldsymbol{m})\end{array}$ & $\begin{array}{c}\text { Disp. } \\
\left(\boldsymbol{m}^{\mathbf{3}}\right)\end{array}$ & $\begin{array}{c}\text { Flange } \\
(\boldsymbol{m})\end{array}$ \\
\hline Pontoon1 & $\begin{array}{l}\text { Elliptical with } \\
\text { keel plate }\end{array}$ & $72 * 25$ & 13633 & $6.0 * 0.5$ \\
Pontoon2 & $\begin{array}{l}\text { Elliptical } \\
72 * 25\end{array}$ & 13289 & No Flange \\
\hline
\end{tabular}

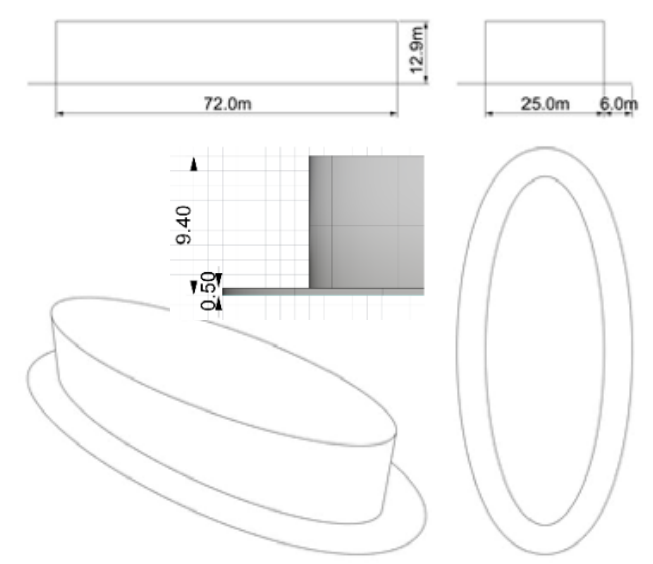

Fig. 1 Geometry information of the elliptical model with keel plate (Pontoon1) used for production. Draft and total height are $9.4 \mathrm{~m}$ and $12.9 \mathrm{~m}$, respectively. From Ref. [13].

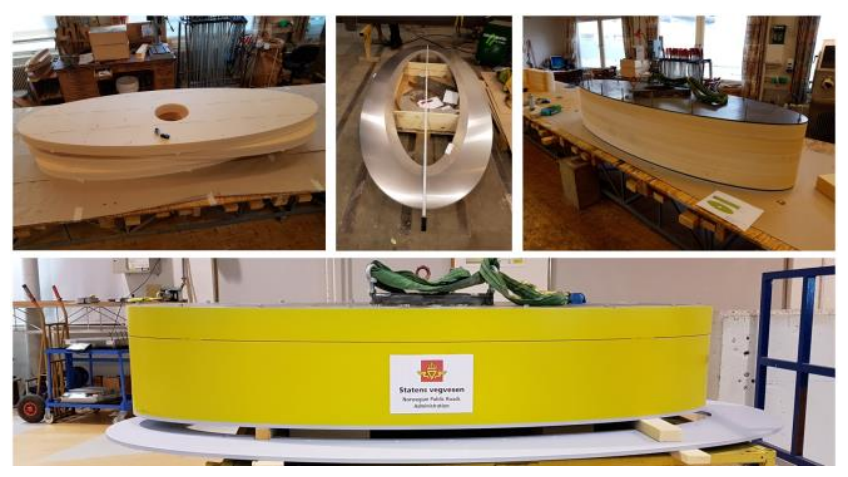

Fig. 2 Production of elliptical model (Pontoon1/1b). From Ref. [13].

Overview of the elliptical pontoons that are relevant for the present study is shown in Table 1 . The model scale is $\lambda=$ $1 / 30$. This model scale is chosen based on both the wave maker and current generation capacity, in addition to the capacity of the forced motion mechanism, under the target wave and current testing conditions.

The model geometry definition for the elliptical pontoon and the keel plate is shown in Fig. 1 and the model in production is shown in Fig. 2. The model is made such that the keel part can be removed and fixed to the pontoon part easily.

\subsection{Model test program}

Restrained model in regular waves and forced harmonic oscillations of the model in surge, sway, heave, roll and pitch are tested. The purpose of the model tests was to obtain hydrodynamic coefficients that can be used to calibrate the numerical tools and the empirical coefficients that are being used in the early phases of pontoon design.

For wave diffraction tests of the restrained model in regular waves, the incident wave amplitudes and periods are 
summarized in Table 2. For the forced harmonic oscillations, the oscillatory periods and amplitudes are listed in Table 3.

Table 2 Test cases with restrained model in regular waves under 0 deg and $45 \mathrm{deg}$ heading angles.

\begin{tabular}{l|rrrrr}
\hline Wave period (s) & 3.5 & 5 & 6 & 7 & 15 \\
\hline $\begin{array}{l}\text { Wave amplitudes } \\
(\mathrm{m})\end{array}$ & 0.3 & 0.7 & 1.6 & 1.5 & 1.5 \\
\hline
\end{tabular}

Table 3 The periods and amplitudes of forced harmonic motions for the pontoons with and without bottom flange.

\begin{tabular}{l|cc}
\hline \multicolumn{1}{c|}{ DOF } & $\begin{array}{c}\text { Periods } \\
{[\mathrm{s}]}\end{array}$ & $\begin{array}{c}\text { Amplitudes } \\
{[\mathrm{m}, \mathrm{deg}]}\end{array}$ \\
\hline Surge, sway, heave & $3.5,5,6,7,10,15$ & $0.3,0.6$ \\
Roll, pitch & $3.5,5,6,7,10,15$ & $2.0,4.0$ \\
\hline
\end{tabular}

\section{CFD ANALYSIS FOR A CROSS SECTION}

As CFD analysis with proper turbulence modelling in $3 \mathrm{D}$ is still too time consuming, it is decided to run 2D CFD analyses for a mid-ship cross section of the pontoon with bottom flange to get some understanding of the viscous flow separation effect and the scale effect. Forced oscillations of the cross section in infinite fluid are considered. When the free surface is not modelled in the CFD analysis, no wave radiation damping is present. Thus, the damping may be assumed to be primarily contributed by the quadratic and higher order effects, and the drag coefficients can easily be estimated through Fourier analysis.

A sketch of the cross section to be used in the CFD analysis is shown in Fig. 3. Here $L$ is the total length of the bottom plate. $B$ and $h$ are the width and thickness of the flange, respectively. $H$ is the draft. In full scale, we have $L=37 \mathrm{~m}$, $B=6 \mathrm{~m}, h=0.5 \mathrm{~m}$ and $H=9.4 \mathrm{~m}$.

In this study, we will use both model-scale and full-scale CFD analyses to study the scale effects, which are either not feasible, or too expensive to study experimentally.

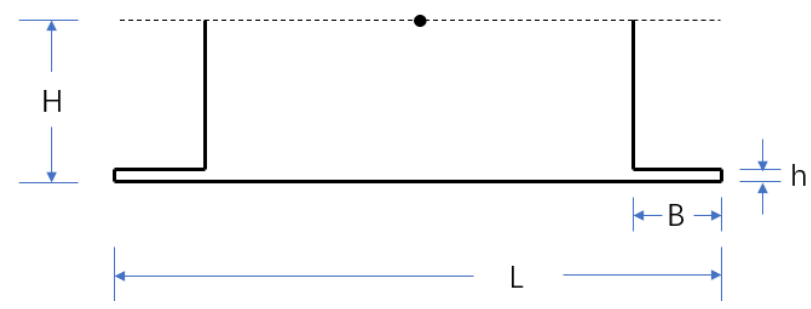

Fig. 3 Sketch of the cross section in the CFD analysis.

\subsection{Numerical model in Star CCM+}

Forced oscillations of a pontoon cross section under different periods and motion amplitudes are studied. Only oscillations in heave and pitch are considered. The oscillatory periods and amplitudes are in accordance with the model tests described in Section 2. Both model scale $(1 / 30)$ and full scale are analysed, leading to a total of 24 simulation cases. The test cases in CFD are summarized in Table 4.

Table 4 The periods and amplitudes of forced oscillations in heave and pitch for the pontoon cross section.

\begin{tabular}{l|cc}
\hline \multicolumn{1}{c|}{ DOF } & $\begin{array}{c}\text { Periods } \\
{[\mathbf{s}]}\end{array}$ & $\begin{array}{c}\text { Amplitudes } \\
{[\mathbf{m}, \mathbf{d e g}]}\end{array}$ \\
\hline Heave & $3.5,5,5.5,6,6.5,7,10,15$ & $0.3,0.6$ \\
Pitch & $3.5,5,5.5,6,6.5,7,10,15$ & 2 \\
\hline
\end{tabular}

Convergence studies in terms of mesh size and time step have been carried out to ensure the accuracy of the numerical results. An example of the mesh used in the analysis is shown in Fig. 4. In order to capture the flow field around the flange, the meshes are refined in the vicinity of the flange. Away from the flange, coarser meshes are applied.

Fig. 5 shows the time series of the normal forces on the flanges part of the section under forced harmonic heave motions. The heave amplitude is $0.6 \mathrm{~m}$ and the heave period is $6 \mathrm{sec}$. The results from four different meshes are compared in the same figure. The obtained drag coefficients for the flange $C_{d \text {,flange }}$ are presented in Fig. 6, which shows satisfactory convergence. The results of convergence study in time step is also shown in Fig.7.

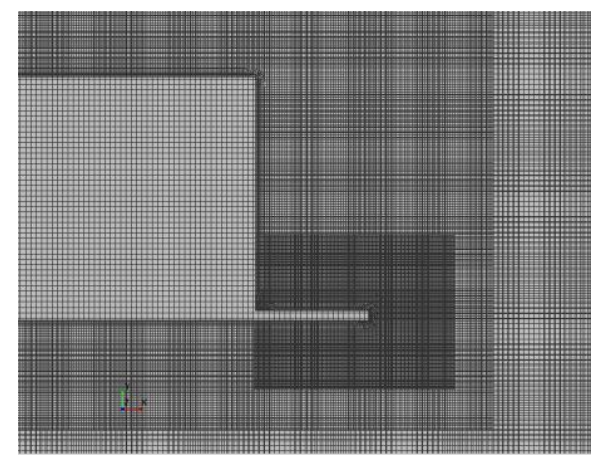

Fig. 4 Example of meshes around the pontoon cross section. Only half of the model is shown.

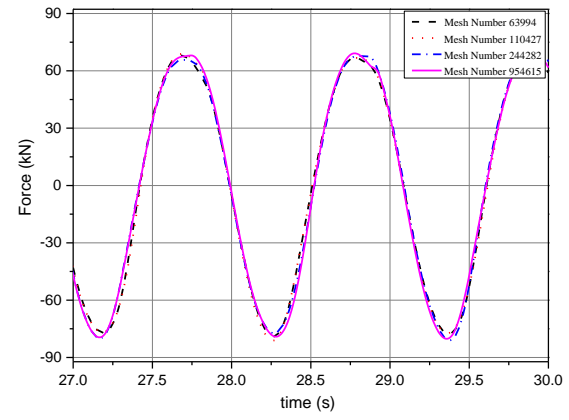

Fig. 5 Normal force time series for the flange based on four different mesh sizes. Heave amplitude is $0.6 \mathrm{~m}$. Heave period is 6 sec. 


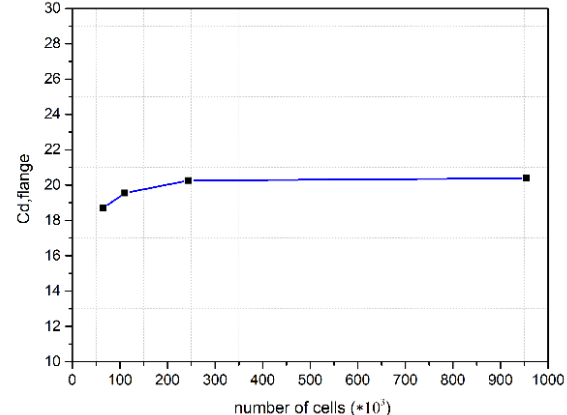

Fig. 6 Mesh convergence study for drag coefficient $\boldsymbol{C}_{\text {d,flange }}$.

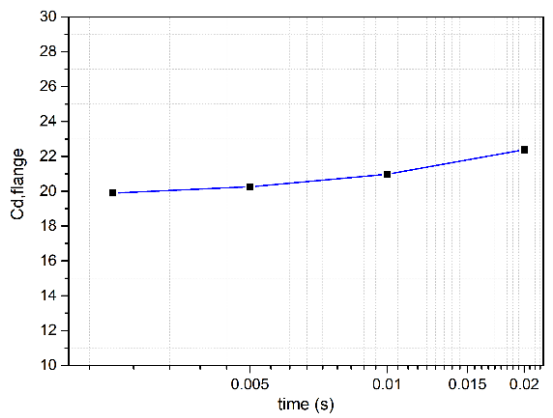

Fig.7 Time step convergence study for drag coefficient $C_{\text {d,flange }}$

\subsection{Numerical results and scale effects}

Both a model scale with scale factor $\lambda=1 / 30$ and the full scale are analysed in the present CFD simulations. The normal drag on the flange and the rest part of the bottom ellipse with the flange excluded are measured separately. The drag coefficients $C_{d \text {,flange }}$ for the flange will be presented using the flange width as characteristic length in the drag force calculation. It means that the drag force on the flange is defined as

$$
F_{d, \text { flange }}=\frac{1}{2} \rho C_{d, \text { flange }} B|u| u .
$$

In this case, the $K C$ number is defined using flange width as characteristic length:

$$
K C_{\text {flange }}=U_{m} T / B .
$$

$U_{m}$ is the relative fluid velocity amplitude. $T$ is the period of the relative velocity. $B$ is the width of flange as defined in Fig. 3. Similarly, the total drag force on the whole pontoon bottom (flange + mid part) can defined as

$$
F_{d, \text { bottom }}=\frac{1}{2} \rho C_{d, \text { bottom }} L|u| u \text {. }
$$

Here $C_{d, \text { bottom }}$ is the drag coefficient on the whole bottom. The corresponding $K C$ number is defined using length of bottom plate as characteristic length

$$
K C_{\text {bottom }}=U_{m} T / L \text {. }
$$

Table 5 summarized the $K C$ numbers in Eq.(2) and Eq.(4) using flange width and bottom length as characteristic lengths, respectively. The considered heave amplitudes are $0.3 \mathrm{~m}$ and $0.6 \mathrm{~m}$.
Table $5 K C$ numbers using flange width and bottom length as characteristic length for heave amplitude $0.3 \mathrm{~m}$ and $0.6 \mathrm{~m}$.

\begin{tabular}{c|cc}
\hline & $\boldsymbol{K}_{\text {flange }}$ & $\boldsymbol{K C}_{\text {bottom }}$ \\
\hline $\mathrm{A}=0.3 \mathrm{~m}$ & 0.314 & 0.051 \\
$\mathrm{~A}=0.6 \mathrm{~m}$ & 0.628 & 0.102 \\
\hline
\end{tabular}

\subsubsection{Drag coefficients on flange}

The drag coefficients on flange from model scale and full scale are shown in Fig. 8. Model-scale CFD results for $K C=0.314$ and $K C=0.628$ are included, corresponding to oscillatory amplitudes of $0.3 \mathrm{~m}$ and $0.6 \mathrm{~m}$ in full scale, respectively. See Eq.(1) and Eq.(2) for the definition of $C_{d, \text { flange }}$ and $K C$ number, respectively. Full-scale CFD results for $K C=0.628$ is also included in the same figure.

The second horizontal axis on the top of the figure is the $\beta$ number $\left(\beta=\frac{S^{2}}{v T}\right)$ in full scale. Here $S$ is the characteristic length, which is taken as flange width in this case. $v$ is the kinematic viscosity coefficient of the fluid. $T$ is the oscillatory period. The corresponding $\beta$ number in model scale is of order of $10^{4}$, which is much smaller than that in the full scale. As seen from the comparison of $C_{d \text {,flange }}$ for model scale and full scale, the scale effect is not significant, except for at a longer period of $15 \mathrm{sec}$. On the other hand, $C_{d, \text { flange }}$ is larger in smaller $K C$ numbers than that in larger $K C$ numbers.

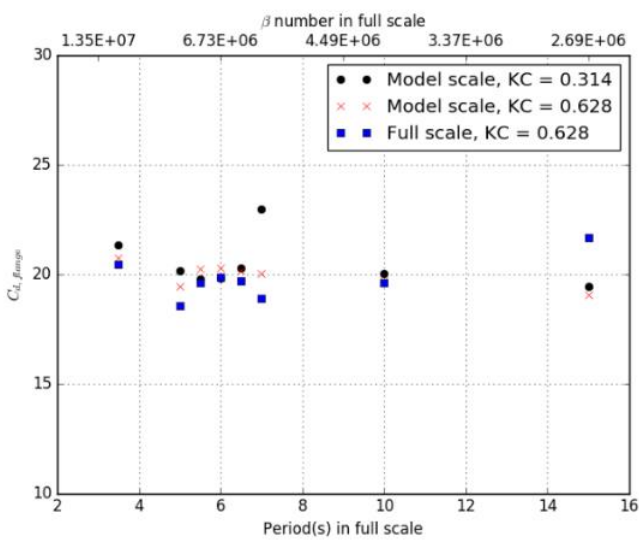

Fig. 8 2D CFD results for drag coefficients on the flange at the bottom of the cross section. $K C$ numbers of 0.314 and 0.638 are studied. The results are plotted as function of oscillatory periods in full scale and $\beta$ number (second axis on top of the figure).

\subsubsection{Total drag on bottom plate}

The drag coefficients $C_{d, \text { bottom }}$ on the whole bottom plate from model scale and full scale are shown for $K C=0.102$ in Fig. 9. The second horizontal axis on the top of the figure is the $\beta$ number in full scale. The corresponding $\beta$ numbers in model scale are much lower, 
which are not shown in the figure. Here the characteristic length $S$ is taken as the length of the bottom plate. See Eq.(3) and Eq.(4) for the definition of $C_{d, b o t t o m}$ and $K C$ number. It is seen that the drag coefficients in model scale and full scale are close to each other, indicating that the scale effect is small for the studied cases.

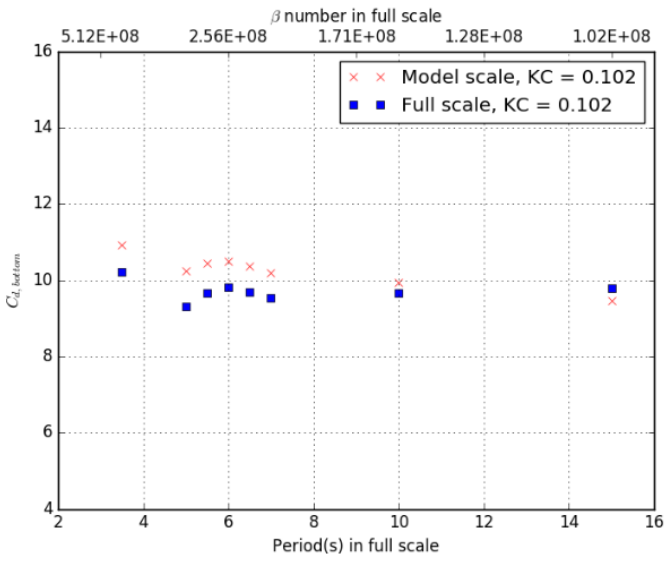

Fig. 9 2D CFD results for drag coefficient on the bottom plate of the cross section. $K C=0.102$ is considered. The results are plotted as function of oscillatory periods and $\beta$ number (second axis on top of the figure).

One should note that the total drag forces contain two parts, one contributed by the flange and the other by the middle part of the bottom plate without the flange. The drag loads (forces and moments) on the flange and the middle part of the bottom plate were measured separately. The contribution from the flange relative to the total drag are summarized in Table 6. It is seen that the drag on the flange dominates the total drag, while the contribution from the rest area on the bottom plate is non-negligible.

Table 6 Ratio as percentage between drag force on the flange and the total drag on the bottom plate.

\begin{tabular}{l|rrrrrrrr}
\hline T (s) & 3.5 & 5.0 & 5.5 & 6.0 & 6.5 & 7.0 & 10.0 & 15.0 \\
\hline $\begin{array}{l}\text { Full } \\
\text { scale }\end{array}$ & $65 \%$ & $65 \%$ & $66 \%$ & $66 \%$ & $66 \%$ & $64 \%$ & $66 \%$ & $72 \%$ \\
$\begin{array}{l}\text { Model } \\
\text { scale }\end{array}$ & $62 \%$ & $62 \%$ & $63 \%$ & $63 \%$ & $63 \%$ & $64 \%$ & $64 \%$ & $65 \%$ \\
\hline
\end{tabular}

With the drag forces/moments measured separately for the flange and the rest part of the bottom plate, the "point of action' of the total drag force on the bottom plate can also be estimated. For the studied 2D cross section under forced heave motions at $0.6 \mathrm{~m}$, the 'point of action' of the drag load is approximately $0.3 L$ from the center of the model.

\section{SIMPLIFIED FREQUENCY-DOMAIN ANALYSIS}

For large volume offshore structures, it is commonly understood that potential-flow contribution to the wave loads is dominant while the viscous flow effects are secondary and can be empirically accounted for. However, damping and excitation forces become equally important in the resonant regime for a dynamic system. In fact, it is challenging to accurately predict the motion of marine structures with damping devices near the resonance. A CFD method based on Navier-Stokes equations with turbulence modeling is obviously the most sophisticated way to handle the viscous effects. However, it becomes computationally too expensive to use it in the design loop of the marine structures, in particular the early phases of the design. Model tests studies are often carried out for the selected cases when the design is more maturated.

A more popular approach incorporating the viscous effects in the early design phases is to use Morison's equation. To use the standard panel method and remain in the frequency domain, the drag term has to be linearized based on, for instance, regular wave linearization or stochastic linearization. In case of the so-called regular-wave linearization method, equivalent linear damping coefficient is found by requiring that the equivalent damping dissipate the same amount of energy as the quadratic damping does over one cycle of oscillation. In this method, a wave amplitude is required as input to the linearization scheme. The method of stochastic linearization directly takes into account the characteristics of the wave spectrum. By assuming that the excitation is a Gaussian stochastic process, the equivalent linear damping is found after minimizing the errors in the least square sense.

This section gives only very brief description of the frequency-domain analysis with the linearized drag forces. The readers are referred to [2], [4], [14] and [15] for more details.

\subsection{Linear frequency-domain analysis}

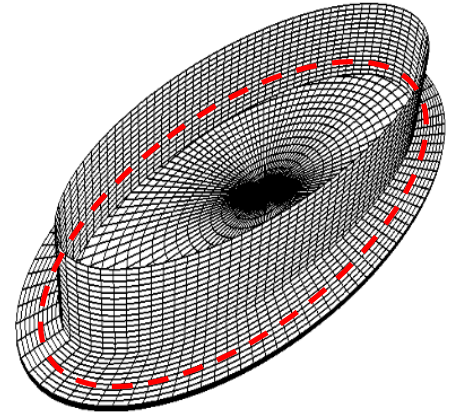

Fig. 10 Panel model (black solid) and Morison model (red dash) for pontoon with bottom flange. Only the part under mean water line is shown.

The linear potential-flow added mass, damping and excitation forces can be obtained from a linear frequencydomain radiation/diffraction program, e.g. WAMIT and WADAM. A panel model in WADAM for pontoon with bottom flange is shown in the figure below. Mesh convergence has been performed and the results presented in the later sections are based on a mesh resolution that gives sufficient accuracy of the linear hydrodynamic 
coefficients. It should be noted that, it is much more computational demanding to obtain convergent secondorder wave loads for structures with sharp edges when a near-filed method based on pressure integration on the wetted structure surface is applied [16], [17] and [18].

\subsection{Drag force linearization}

Since the studied cases in this paper concern diffraction in regular waves and forced harmonic motions in otherwise calm water conditions, only regular wave linearization will be used. In regular-wave linearization, the drag force on a strip of length $d l$ of a Morison element is

$$
\begin{aligned}
d \boldsymbol{F}_{\boldsymbol{D}} \approx \frac{1}{2} \rho \boldsymbol{C}_{\boldsymbol{D}} D \frac{8}{3 \pi} & |\boldsymbol{v}-\dot{\boldsymbol{x}}|_{\text {amp }}(\boldsymbol{v}-\dot{\boldsymbol{x}}) d l \\
& =b_{v}(\boldsymbol{v}-\dot{\boldsymbol{x}})
\end{aligned}
$$

where

$$
b_{v}=\frac{1}{2} \rho C_{D} D \frac{8}{3 \pi}|\boldsymbol{v}-\dot{\boldsymbol{x}}|_{\text {amp }} d l .
$$

Here $v$ is the ambient flow velocity. $\dot{x}$ is the motion velocity of the strip. $|\boldsymbol{v}-\dot{\boldsymbol{x}}|_{\text {amp }}$ is the amplitude of the relative velocity between ambient flow and the structure at the location of the Morison element. $b_{v}$ represents the linearized damping coefficient contributed by a strip of length $d l$.

To get the complete equivalent coefficients, one has to integrate Eq.(5) on each element and sum up the contribution from all the Morison elements. In this paper, the ambient flow velocity is taken as fluid particle velocity of the undisturbed incident wave. Therefore, the first term $b_{v} v$ in Eq.(5) represents a viscous correction to the wave excitation loads and the second term $-b_{v} \dot{x}$ contributes to the damping forces/moments due to the drag forces.

\subsection{Morison model}

In the present study, Morison elements are distributed along an elliptical curve on the bottom disk, which is illustrated by the red dash line in Fig. 10. The defined Morison elements give only vertical drag force perpendicular to the bottom flange. 40 Morison elements are used in all the cases presented in this study. No Morison elements in other parts, e.g. the vertical main hull, are applied as the focus in this paper is the vertical motions of the pontoon.

The drag coefficient $C_{d}$ to be applied on each Morison element is $K C$ number dependent. For forced heave motion in otherwise calm water, the $K C$ number is the same on all Morison elements, thus the same $K C$ number can be used for the selection of $C_{d}$. For forced pitch motion and restrained pontoon in waves, $K C$ numbers are location dependent and a proper drag coefficient is selected for each element. The selection of drag coefficient will be discussed in the next section.

\section{NUMERICAL RESULTS}

\subsection{Definitions of drag coefficients}

As explained in Section 3.2, two different ways of defining the drag forces from the literature might be used to estimate the viscous loads on a heaving pontoon with a bottom flange. In the first definition, the drag and inertia forces on the bilge box are described based on Morison's equation by considering the bilge box as slender structure. This implicitly assumes that the viscous forces contributed from the flange is dominant, and the contribution from the middle part of the bottom plate, is negligible or can be estimated separately. This definition also has relevance for the bilge keels on ships. It has been used, for instance, in [19] for wall-mounted plates and in [20] for the skirt of the CALM buoy. In this case, the relevant $K C$ number can be defined by Eq.(2) using flange width as the characteristic length.

The second definition of the drag forces has been used by, for instance in [3], [21] and [22], to model the vertical drag force on the forced heaving disk attached to a cylinder. In this definition, it is not straightforward to reflect the distribution of the viscous forces contributed by different parts of the structure, for example, the pressure force on the flange and the rest parts of the pontoon.

In this study, the Morison elements with linearized drag force on each element have been implemented to account for both the viscous forces and moments around the reference point of interests. To do that in a proper and practical manner, the summation of the drag forces on the Morison elements should be the same as the total drag forces on the bottom plate. On the other hand, the locations of the Morison elements should be calibrated based on the knowledge of the pressure distribution on the whole structure to properly represent the moments. In general, it is not easy or feasible to obtain detailed pressure distribution through model tests.

In Section 3.2.2, attempt has been made in CFD analysis to find the 'point of act' for the total drag force on the bottom plate of a $2 \mathrm{D}$ cross section of the pontoon with flange. This type of analysis could be extended to $3 \mathrm{D}$ in the future studies.

\subsection{Empirical drag coefficients using flange length as characteristic length}

For the wall-mounted plates, the $C_{d}$ coefficients obtained from model tests have been reported for a large range of $K C$ numbers in Sarpkaya \& O'Keefe [19]. Cozijn et al. [20] has studied forced oscillations of CALM buoy with different skirt in model tests. Drag coefficients have been obtained through numerical calibration using skirt width as characteristic length for drag and comparison has been made with those of [19]. 
Fig. 11 shows a few different $\boldsymbol{C}_{\boldsymbol{d}}$ coefficients: the $\boldsymbol{C}_{\boldsymbol{d}}$ coefficients for wall-mounted plates from Sarpkaya \& O'Keefe [19]; the $\boldsymbol{C}_{\boldsymbol{d}}$ coefficients for two different skirts of the CALM buoy under heave or pitch motions [20]; and $\boldsymbol{C}_{\boldsymbol{d}}$ coefficients from the present CFD analysis for the heaving mid-ship cross section. ' $2 D$ CFD flange_only' represents the model-scale CFD results for $\boldsymbol{C}_{\boldsymbol{d} \text {,flange }}$ in Fig. 8, while '2D CFD total' shows $\frac{\boldsymbol{L}}{\boldsymbol{2 B}} \cdot \boldsymbol{C}_{\boldsymbol{d}, \boldsymbol{b o t t o m}}$, where $\boldsymbol{C}_{\boldsymbol{d}, \boldsymbol{b o t t o m}}$ is the model-scale CFD results in Fig. 9.

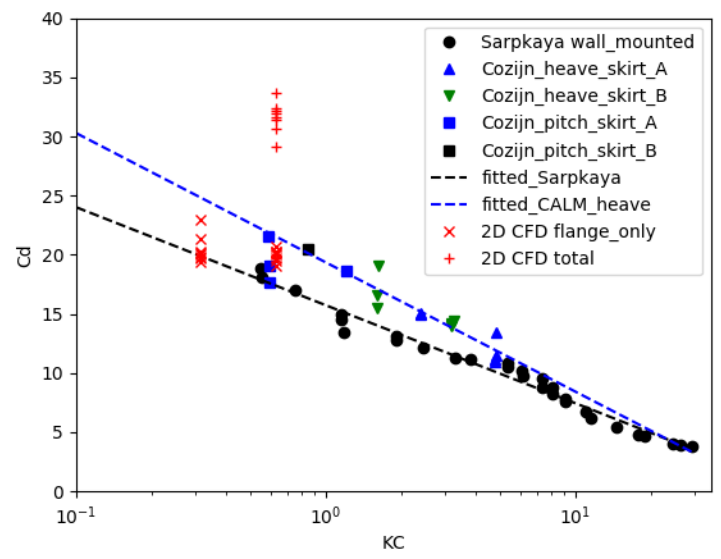

Fig. 11 Drag coefficients as function of $K C$ number for wallmounted plates [19], two different heaving skirt of CALM buoy [20], and heaving mid-ship cross section of pontoon with bottom flange. The dash lines are fitted curves using $S$ the data except for the 2D CFD results.

In general, the drag coefficients obtained in [20] were larger than those for the wall mounted plates in [19]. It was explained in [20] that the 3D effects may have been the reason for the difference. It should also be noted that the flange drag coefficients calibrated in [20] contain the contribution from the whole bottom disk (but not only the skirt alone). As seen from CFD analysis in Section 3.2.2 for a $2 \mathrm{D}$ cross section, the flange contributes only a part of the total drag force and the contribution from the middle part of the bottom plate excluding the flange is non-negligible.

As seen in Fig. 11, our 2D CFD results for the flange seem to agree better with that for the wall-mounted plates. On the other hand, the coefficients $\frac{L}{2 B} \cdot C_{d, \text { bottom }}$ which include the total drag on the bottom plate but using flange width as characteristic length for the definition of the drag force, are higher than that of [19] and [20]. This might be explained partially by the 3D effects in the model tests in [19] and partially by the fact that drag coefficients in [20] only concern drag forces on wall-mounted plates.

The black dash line in Fig. 11 is a fitted curve using $\boldsymbol{C}_{\boldsymbol{d}}$ of wall-mounted plates [19], which takes the following form:

$$
C_{d}=-3.597 \cdot \log (K C)+15.733 .
$$

The red dash line in Fig. 11 is a fitted curve using $\boldsymbol{C}_{\boldsymbol{d}}$ coefficients for heaving CALM buoy with two different skirts [20], which is described by:

$$
C_{d}=-4.744 \cdot \log (K C)+19.354 .
$$

Cozijn et al. [20] have also reported $\boldsymbol{C}_{\boldsymbol{d}}$ coefficients based on the forced pitch motions of the CALM buoy. Those results are not used in the curve fitting, as $K C$ numbers are different at different places of the skirt under forced pitch motions.

The fitted curves by Eq.(7) and Eq.(8) for drag coefficient are strictly speaking not valid at lower $K C$ number where no experimental data are available. Asymptotically, one could also expect $C_{d} \propto K C^{-1 / 3}$ for a flat plate when $K C \rightarrow$ 0 . The fitted curves also give unphysical drag coefficients for $K C>30$, since no data were available in that regime. The $K C$ numbers for the considered floating bridge pontoons are typically smaller than 1.0 in this study.

Considering the data that have been used in the fitting, one may use Eq.(7) to estimate the drag loads due to the flange only, while $C_{d}$ based on Eq.(8) is more relevant to total drag on the bottom plate.

\subsection{Results for pontoon with bottom flange}

This section presents the experimental results and numerical results based on the frequency-domain analysis with linearized drag forces. More details on the numerical method can be found in Section 4 and Shao et al. [2]. Results using drag coefficients from Eq.(7) and Eq.(8) will be shown in Sections 5.3.1 and 5.3.2, respectively. All the results are presented for pontoon with bottom flange in full scale.

Different types of results will be presented in this section and Section 5.4. In specific, 'Pot.' is the potential-flow results without any linearized drag forces. 'Pot. $+\mathrm{Cd} .0 .3$ $m$ ' and 'Pot. $+C d .0 .6 \mathrm{~m}$ ' represent results with forced heave amplitude of $0.3 \mathrm{~m}$ and $0.6 \mathrm{~m}$ in the linearized drag loads, respectively. ' $M T 0.3 \mathrm{~m}$ ' and ' $M T 0.6 \mathrm{~m}$ ' are the corresponding model-test results for heave amplitudes of $0.3 \mathrm{~m}$ and $0.6 \mathrm{~m}$, respectively. Similarly, 'MT $2.0 \mathrm{deg}$ ' and 'MT $4.0 \mathrm{deg}$ ' are the corresponding model-test results for pitch amplitude of 2 and 4 degrees, respectively.

In this study, we have not attempted to empirically account for the viscous effects on the inertia forces, thus the numerical results for added mass are the same with and without drag forces. In principal, it is possible to include viscous correction to the inertia loads in the Morison model, which is not pursued in this paper.

\subsubsection{Numerical results using $C_{d}$ from Eq.(7)}

As a starting point, we considered the flange as a slender structure and applied the linearized drag forces on Morison elements using the drag coefficients based on Eq.(7) for the 
wall-mounted plates. The Morison elements are located at the centre of the flange. The $K C$ number at each Morison element is firstly estimated and a corresponding $C_{d}$ value using the fitted $C_{d}$ function will be applied on the corresponding element.

The linearized heave-heave and pitch-pitch damping coefficients are then compared with the model test results in Fig.12. As seen from the comparison, the present damping coefficients are smaller than that of the experiments, indicating the applied drag forces are too small. This is expected, as the drag coefficients based on Eq.(7) do not include the drag forces on the whole bottom plate.

On the other hand, the numerical results slightly over predicted the pitch-pitch damping coefficients, which means that the Morison elements should have been shifted towards the centre of the bottom plate.

It is believed that the applied $C_{d}$ based on Eq.(7) and the location of Morison elements have not been properly calibrated. Therefore, no other results will be shown in this section rather than those in Fig.12.
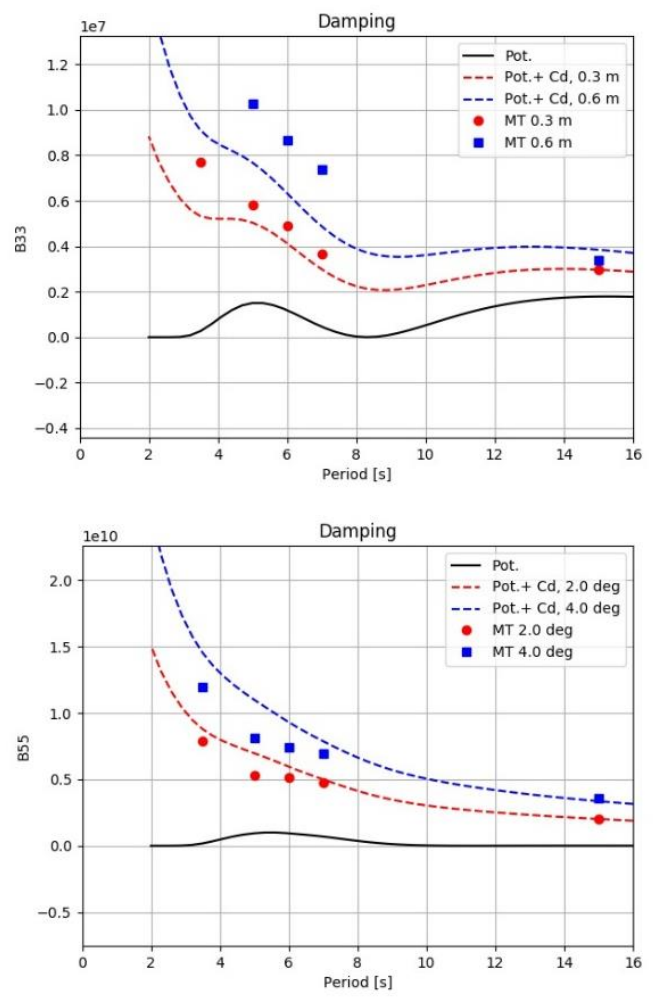

Fig.12 Heave-heave and pitch-pitch damping mass coefficients. The corresponding wave periods and amplitudes for model tests are defined in Table 4. Upper: heave damping $B_{33}$; Lower: pitch damping $B_{55}$.

\subsubsection{Numerical results using $C_{d}$ from Eq.(8)}

Numerical results using the fitted drag coefficients from Eq.(8), which include contribution from whole bottom plate, will be compared with experimental results in this section.

\section{Added mass and damping coefficients}

The heave-heave and pitch-pitch added mass are shown in Fig. 13, and the corresponding damping coefficients are presented in Fig. 14.

It is seen from Fig. 14 that the heave damping matches much better with the experiments than that in Fig.12, indicating the drag coefficient in Eq.(8) with total drag effects on the bottom plate might be a better option. The Morison elements were distributed along on an ellipse, which has semi-major radius $R_{a}=0.75 R_{a, 0}$ and semi-minor radius $R_{b}=0.65 R_{b, 0}$. Here $R_{a, 0}$ and $R_{b, 0}$ are semi-major radius and semi-minor radius of the bottom ellipse.

It is also observed from the added mass results that the potential-flow results are in general lower than that of the model tests. However, this has not been the focus of the present study. Further study should involve 3D CFD analysis with proper turbulence modelling and quantifying the uncertainties of the model test results.
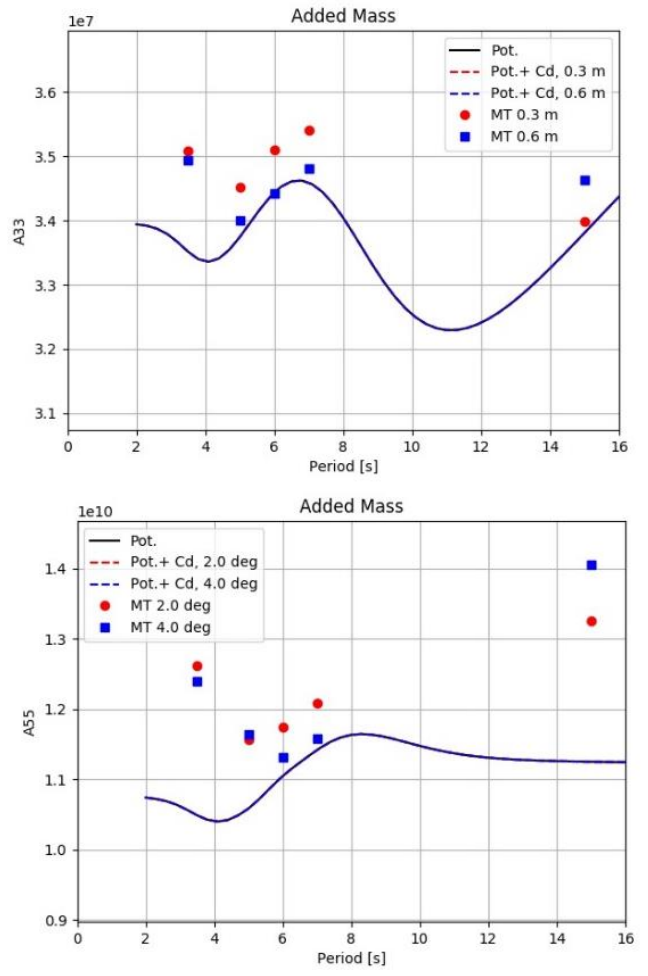

Fig. 13 Heave-heave and pitch-pitch added mass coefficients. The corresponding wave periods and amplitudes for model tests are defined in Table 4. Upper: heave added mass $A_{33}$; Lower: pitch added mass $A_{55}$. 

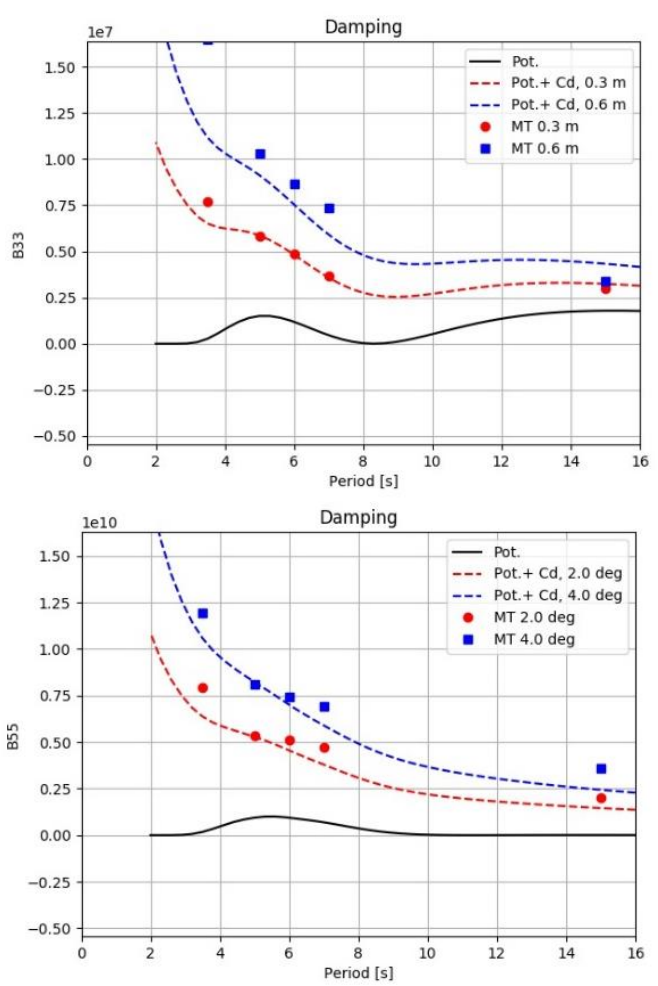

Fig.14 Heave-heave and pitch-pitch damping mass coefficients. Upper: heave added mass $A_{33}$; Lower: pitch added mass $A_{55}$.
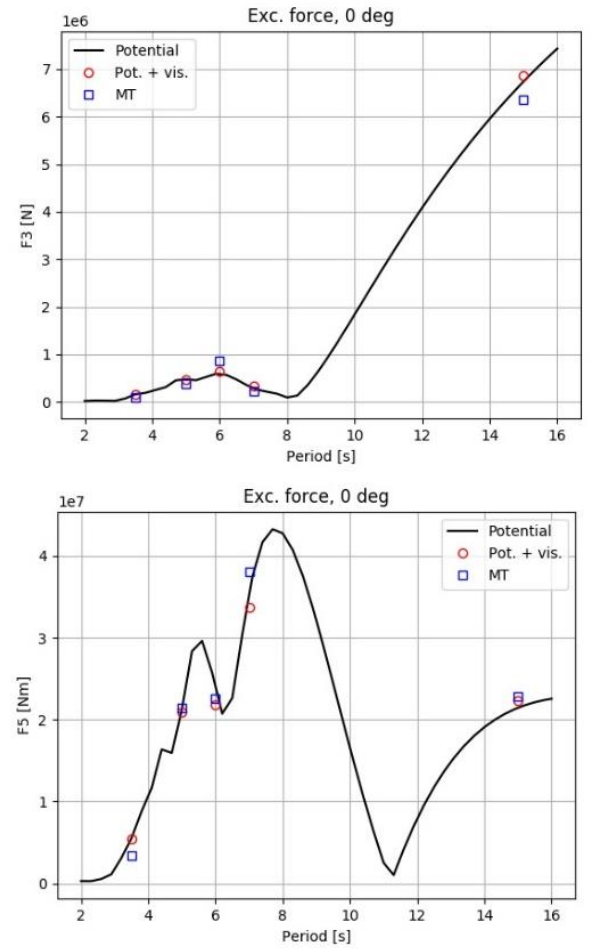

Fig. 15 Wave excitation load per unit incident wave amplitude with 0 deg wave heading. 'MT' represents model test results with the corresponding wave periods and amplitudes defined in Table 2. Upper: heave force; Lower: pitch moment.

\section{Wave excitation forces at 0 deg wave heading}

The wave excitation in heave and pitch per unit incident wave amplitude is shown in Fig. 15. Both potential-flow results with and without viscous correction show good agreement with model tests, indicating a small viscous effect on wave excitation.

\subsection{Pontoon without bottom flange}

Similar simplified frequency-domain analysis with linearized drag forces/moments has been carried out for the ellipse pontoon without bottom flange. The drag coefficients presented in Section 5.2 are more relevant for wall-mounted plated and bottom plate mounted on a vertical cylinder, which have limited relevance for the pontoon without bottom flange. Due to limited space, the details of the numerical calibration will not be shown here.
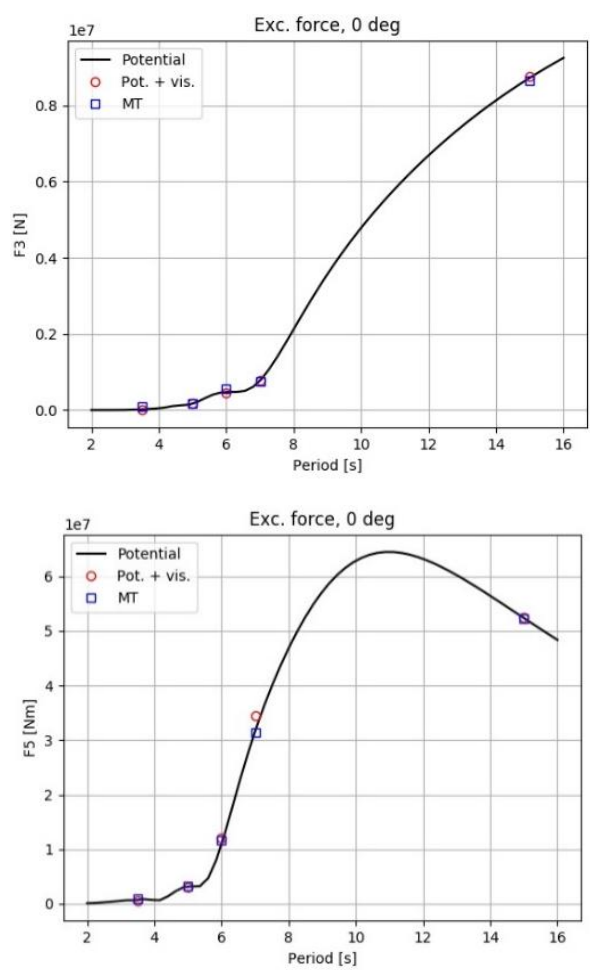

Fig. 16 Wave excitation load per unit incident wave amplitude with 0 deg wave heading. 'MT' represents model test results with the corresponding wave periods and amplitudes defined in Table 2. Upper: heave force; Lower: pitch moment.

The results presented in the rest of this section are based on:

(1) A total drag coefficient $C_{d, b o t t o m} \approx 5.0$ is applied for the bottom plate.

(2) Morison elements are distributed on the bottom plate along an elliptical ring (see Fig. 10 for illustration), which has semi-major radius $R_{a}=0.85 R_{a, 0}$ and semiminor radius $R_{b}=0.85 R_{b, 0}$. Here $R_{a, 0}$ and $R_{b, 0}$ are semi-major radius and semi-minor radius of the bottom ellipse. The total drag force contributed by the Morison elements should be the same as total drag force, which 
is expressed by drag part of the Morison-type formula $F_{d, \text { bottom }}=\frac{1}{2} \rho C_{d, \text { bottom }} S|u| u$. Here $S$ is the projection area. $u$ is the relative velocity.

The wave-excitation force in heave and moment in pitch per unit wave amplitude for 0 deg wave heading are presented in Fig. 16. The small differences between potential-flow results with/without linearized drag and model test results indicate that smallness of the viscous effects on wave excitation.

The added mass coefficients based on linear potential-flow analysis also show good agreement with model test (heave amplitude of $0.3 \mathrm{~m}$, pitch amplitude of $2 \mathrm{deg}$ ), except for oscillatory period of $15 \mathrm{~s}$. See Fig. 17 for the comparison. It is expected that the differences between the linear potential-flow results and model test results will increase for larger motion amplitudes.

As seen from Fig.18, the linear potential-flow results underestimate the heave and pitch damping, and clear improvement is seen when the drag loads are included. Comparing the damping coefficients with that of pontoon with bottom flange, one can also understand that the viscous damping due to the presence of the flange is significant.
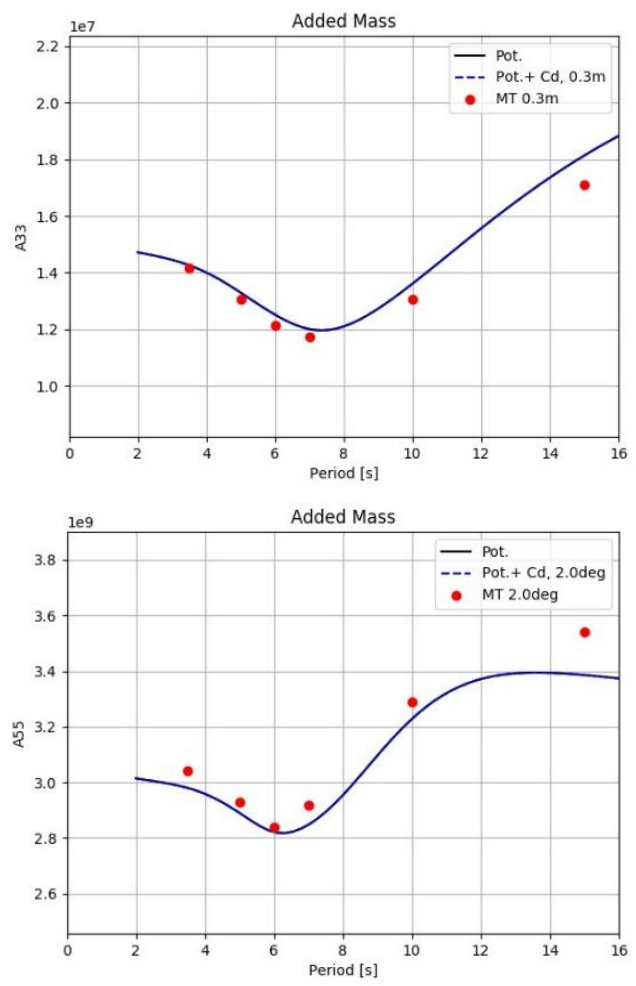

Fig. 17 Heave-heave and pitch-pitch added mass coefficients. The corresponding wave periods and amplitudes for model tests are defined in Table 4. Upper: heave added mass $A_{33}$; Lower: pitch added mass $A_{55}$.
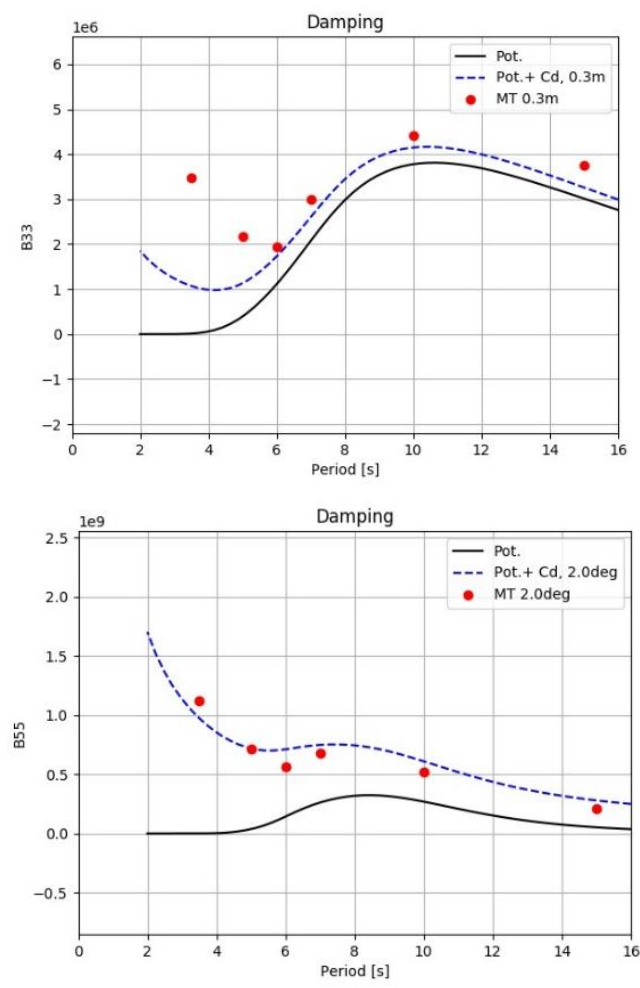

Fig.18 Heave-heave and pitch-pitch damping mass coefficients. The corresponding wave periods and amplitudes for model tests are defined in Table 4. Upper: heave damping $B_{33}$; Lower: pitch damping $B_{55}$.

\section{CONCLUSION AND FUTURE WORK}

Elliptical pontoon with and without keel plate that have been tested in SINTEF Ocean as part of the Norwegian Public Road Administration (NPRA) floating bridge project have been analyzed using a simplified frequency domain approach. The frequency-domain analysis includes linearized drag forces/moments in the wave excitation and damping coefficients. CFD analysis for a $2 \mathrm{D}$ cross section of the pontoon has been carried out to understand the scale effects, drag loads contribution from the flange relative to total drag loads and the 'point of action' of the viscous drag on the bottom plate. Different drag coefficients fitted from that of the wall-mounted plates and CALM buoy with skirts are applied in the abovementioned frequency-domain analysis. It is confirmed that the drag coefficients, which include total drag loads, give much better results. It is also shown that a Morison model is able to predict both heave and pitch damping as long as the drag coefficient and locations of the Morison elements are carefully selected and calibrated.

Future study should focus on 3D CFD analysis as well as the understanding of uncertainties in the model test to address the non-negligible differences in the added mass between model tests and potential-flow analysis. The present study also lays basis for the analysis of floating pontoon in irregular waves, which is an ongoing work. 


\section{ACAKNOWLEDGEMENTS}

The first author would like to acknowledge the support from COWIFonden and DTU Department of Mechanical Engineering.

\section{REFERENCES}

[1] Wikipedia, Evergreen Point Floating Bridge, https://en.wikipedia.org/wiki/Evergreen_Point_Float ing Bridge. Retrieved January 2, 2019.

[2] Shao Y.L., You J.K. and Glomnes E.B.(2016), Stochastic linearization and its application in motion analysis of cylindrical floating structure with bilge box, $35^{\text {th }}$ International Conference on Conference on Ocean, Offshore and Arctic Engineering, June 19-24, Busan, South Korea.

[3] Tao L. and Cai S. (2004), Heave motion suppression of a Spar with a heaving plate, Ocean Engineering 31, 669-692.

[4] Xiang X. et al. (2017), Viscous damping modelling of floating bridge pontoons with heaving skirt and its impact on bridge girder bending moments. The $36^{\text {th }}$ International Conference on Ocean, Offshore and Arctic Engineering, June 25-30, 2017, Trondheim, Norway.

[5] COWI. NOT-KTEKA-021 Curved bridge navigation channel in south - summary of analysis. Report for the Norwegian Public Road Administration.

[6] COWI. NOT-KTEKA-020 Straight bridge navigation channel in south - summary of analysis. Report for the Norwegian Public Road Administration.

[7] Kleppa E. (2017), Numerical analysis of waveinduced responses of floating bridge pontoons with bilge boxes, master thesis at Department of Mechanical Engineering, DTU.

[8] Fredriksen et al. (2017), Hydrodynamic aspects of pontoon optimization for a side anchored straight floating bridge. The $36^{\text {th }}$ International Conference on Ocean, Offshore and Arctic Engineering, June 25-30, 2017, Trondheim, Norway.

[9] Moreto J., Thiagarajan K.P., Cameron M. (2015), Hydrodynamic Coefficients of Hexagonal Heave Plates for Floating Offshore Wind Turbine Platforms, June 19-24, 2016, Busan, South Korea.

[10] Moreto J., Cameron M., Thiagarajan K.P., Mendoza C.A.G. (2015) Hydrodynamic performance of heave plates on floating offshore wind turbine platforms. 25th International Ocean and Polar Engineering Conference, June 21-26, 2015, Hawaii, USA.

[11] Cheng Z., Gao Z. and Moan T., Hydrodynamic load modeling and analysis of a floating bridge in homogeneous wave conditions, Marine Structures, 59, 122-141, 2018.

[12] Xiang X., Viuff T., Leira B. and Øiseth (2018), Impact of hydrodynamic interaction between pontoons and global responses of a floating bridge under wind waves, $37^{\text {th }}$ International Conference on Conference on Ocean, Offshore and Arctic Engineering, June 1722, Madrid, Spain.

[13] Baarholm G.S. et al. (2017), Model Tests for Bjørnafjorden Floating Bridge Concept, SINTEF Ocean, Norway. Report No. OC2017 F-176.

[14] Borgman L.E., 1967, Random Hydrodynamic Forces on Objects, Annals of Mathematical Statistics, pp.3751.

[15] Wolfram, J. (1998): On alternative approaches to linearization and Morison's equation for wave forces, Proc. R. Soc. London, Vol. 455, pp. 2957-2974.

[16] Shao Y. (2018), Numerical Analysis of Second-Order Mean Wave Forces by A Stabilized Higher-Order Boundary Element Method. J. Offshore Mech. Arct. Eng., doi: 10.1115/1.4042197.

[17] Shao Y.L. and Faltinsen OM (2014), A numerical study of the second-order wave excitation of ship springing by a higher-order boundary element method, International Journal of Naval Architecture and Ocean Engineering, 4(4), 1000-1013.

[18] Liang H., Faltinsen O.M. and Shao Y.L. (2015), Application of a 2D harmonic polynomial cell (HPC) method to singular flows and lifting problems. Applied Ocean Research, 53, 75-90.

[19] Sarpkaya T. and O'Keefe J., 1996, Oscillating flow about two- and three dimensional bilge keels, Journal of Offshore Mechanics and Artic Engineering, v.118, pp.1-6.

[20] Cozijn J.L., Uittenbogaard, R. and ter Brake, E., Heave, Roll and Pitch Damping of a Deepwater CALM Buoy with a Skirt, ISOPE2005-jsc-409, ISOPE Conference, Seoul, 2005.

[21] Tao L., and Thiagarajan, K. (2003). Low KC flow regimes of oscillating sharp edges I. Vortex shedding observation. Applied Ocean Research, 25(1), pp. 2135.

[22] Tao L., and Thiagarajan K., (2003), Low KC flow regimes of oscillating sharp edges II. Hydrodynamic forces. Applied Ocean Research 25, pp.53-62. 